Sustainable Development and Planning X 437

\title{
INDICATOR ENGINEERING FOR LAND TAKE CONTROL AND SETTLEMENT SUSTAINABILITY
}

\author{
LORENA FIORINI ${ }^{*}$, ALESSANDRO MARUCCI $^{\dagger}$, FRANCESCO ZULLO $^{\ddagger} \&$ BERNARDINO ROMANO $\$$ \\ University of L'Aquila, Italy
}

\begin{abstract}
In this paper, we describe some indicators used to interpret urban sprawl and some of its effects on the environmental and ecosystem matrix. These are examples taken from a number of research programs that the University of L'Aquila has been engaged in over the past ten years that have produced more than 15 new indicators of urban sprawl and the numerous threats that the latter poses for land and the environment. Using some parameters we were able to prove that the expansive settlement model that prevailed in Italy over the past 50 years does not follow the conventional international standard of sprawl, but has a different pattern named "sprinkling". Other indicators show that this growth is independent of population dynamics, at least at microterritorial level (municipalities), while the result is different on a macroterritorial scale (regions). Furthermore, this highly sprinkled type of settlement also has adverse effects on the fragmentation of ecosystems and biodiversity hot spots and using other indices we were able to highlight these phenomena too, which are scarcely considered as territorial "diseases" that need to be tackled and overcome. Carefully designed sets of parameters, such as those described in this paper, should be included in technologyassisted regional platforms to control and govern land transformation, in order to make the pursuit of improved land planning more efficient than what it is today.

Keywords: indicator engineering, land take, settlement sustainability, urban sprinkling.
\end{abstract}

\section{INTRODUCTION}

The intensive urban development that has occurred in countries worldwide over the past decades is now producing its most harmful consequences, thus fully confirming the alarm raised by the European Commission in early 2000 and by some experts of the international scientific community [1], [2]. Most conventional urban development literature, especially in Italy, has reported this phenomenon almost solely in terms of its effects on landscape, its alteration of the age-old balance between cities and rural areas or social psychology, without identifying - other than in recent years - additional and more severe dysfunctions. These dysfunctions profoundly concern the energy footprint of settlements [3], the fulfillment of the need for social services [4], [5], the fragmentation of nature hot-spots [6][8], the depletion of ecosystem services [9] and environmental risk resilience [10], [11]. In western industrialized countries, at least, there has been a huge and mostly unjustified increase in urban land take, despite minor demographic changes. This is an increase that in some political cultures, such as the Italian one, was viewed as an indicator of good administration by Mayors and Town councils for decades. Even the town planning legislation of Regions has encouraged new constructions as much as possible and the same can be said of tax regulations too. In this regard, national scientific literature has expressed some uncertainty, uncritically classifying the Italian pseudo-dispersed fabric under the

\footnotetext{
* ORCID: http://orcid.org/0000-0002-3071-9644

+ORCID: http://orcid.org/0000-0002-5832-9322

* ORCID: http://orcid.org/0000-0002-9124-0776

§ ORCID: http://orcid.org/0000-0002-5947-1275
} 
international standard of "sprawl" [1], [12]-[19] without considering the clear differences that entail increased recovery difficulties.

Therefore, in Italy's case, a different definition is suggested, namely "sprinkling" [20] as it better conveys the layout of the peninsula's urbanized areas, also present in other Southern European (Iberian, Mediterranean and Balkan) areas however, and, in other continental areas too, albeit in different ways. Although sprinkling is the emblematic layout of urbanized areas in the country's chief plains, nearly the entire national territory is characterized by this form of land take without significant meridian differences.

In the following sections, we will set out a number of indicators developed over several years to respond to different requirements in terms of study and relationship between sprawled urban layout and other territorial, environmental and socio-economic aspects throughout the country and in specific geographical areas.

\section{EXPERIMENTAL DEMO-URBAN INDICATORS}

Between 2006 and 2015 the University of L'Aquila developed a broad range of data and indicators, investigating their qualities and shortcomings in reflecting settlement and environmental effects throughout the country. The set of exemplifying parameters described below are taken from a number of papers in which they were tested and even applied to territorial governance documents [20]-[26].

\subsection{Model indicators: sprawl vs. sprinkling}

The main result of our study, highlighting that the settlement development model followed its own specific course for several decades, was reached by analyzing the distribution models of urbanized areas using the Urban Dispersion Index - UDI, formulated as follows and applied to all Italian regions on a consistent grid of $1 \mathrm{kmx} 1 \mathrm{~km}$ plots (Fig. 1), together with Urbanization Density (UD).

Urbanization Density (UD) indicates the size of areas transformed for varying purposes in a given territorial zone. On a national scale, data is available mostly for "urbanization", that is to say areas used for settlement-related purposes. Today, we can extrapolate data from various databases, such as regional Land Use Maps (generally on a scale varying between 1:10.000 and 1:5.000), or satellite data (Copernicus - https://spacedata. copernicus.eu/) again on a scale of 1:10.000.

$$
\begin{aligned}
& U D=\frac{\sum A e d_{i}}{A u}, \\
& U D I=\frac{N u c}{A u,}
\end{aligned}
$$

where:

$\operatorname{Aed}_{i}=$ surface covered by buildings or sealed/urbanized layers

$N u c=$ number of urbanized centers

$A u=$ surface of the reference territorial unit $\left(\mathrm{km}^{2}\right)$

A UDI increase over time (UDI+) highlights the rise in the number of separate urban cores within the reference area and therefore always corresponds to an increase in dispersed urbanization density (UD). A UDI drop (UDI-), instead, shows a reduction in separate urban cores and therefore the densification of existing ones with an increase in UD. When UDI is constant (UDI 0 ), we can have two conditions: if UD increases (UD+), it means that existing urban cores have grown in size, with new urbanized parts in contact with existing 
ones (UDI 0 ). If $\mathrm{UD}=0$ too, then it means that there are no changes compared to the initial state (No change) (Fig. 1(a)).

The diagrams in Fig. 1(b) show that in Italy the prevailing model of urban growth is the one of significant dispersion (UDI+). On average, all regions have done little to densify settlements (30\% of the territory at the most) and have essentially avoided aggregated urban growth (UDI0+DU) which rarely exceeds $10 \%$ of the territory but which instead is a generalized standard in Northern European countries.

\subsection{Demo-urban dynamic indicators}

The correlation between population dynamics and urbanization is very important as it helps develop models and apply inferential analysis to devise reliable prospective scenarios. As shown in the diagrams in Fig. 2, although falling within the previously mentioned prevailing proportionality on a regional scale, on a municipal scale the differences between Italian regions and geographical sectors are numerous. The diagrams in Fig. 2 were all contained within the $300 \%$ population and $1500 \%$ urbanized area increases, since all municipalities fall in these ranges across all the regions. There are, of course, higher values, but these concern very few cases. Amongst central Italian regions, Fig. 2 shows that only Umbria and Marche have a strong match between urbanization and population (where most municipalities do not exceed $400 \%$ ). The models of the other central and southern regions share many similarities, with seven having stable demographic values matched by increases in urbanized areas ranging between $200 \%$ and $600 \%$.

Changes in urban layout strongly depend on the population size of municipalities and their geographical relationship with the main metropolitan areas in the country. Fig. 3 uses the population size brackets of municipalities adopted by ISTAT (Central Institute of Statistics) and shows a very similar polynomial distribution for both demographic $(\Delta \mathrm{Dem})$

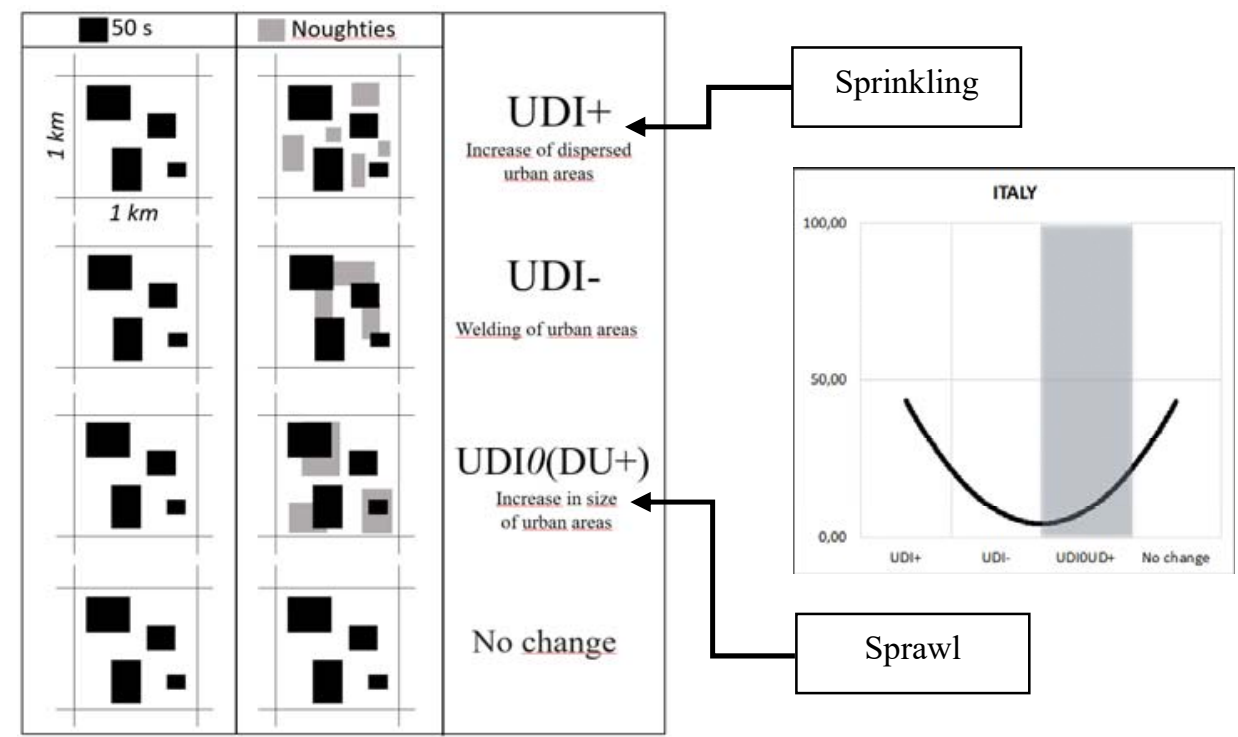

Figure 1: (a) Models of urban growth in the timespan considered (50s-Noughties); (b) Models of urban growth in Italy obtained by combining the UDI and UD indicators. In grey the model UDI0(UD+) (aggregated urban growth). 


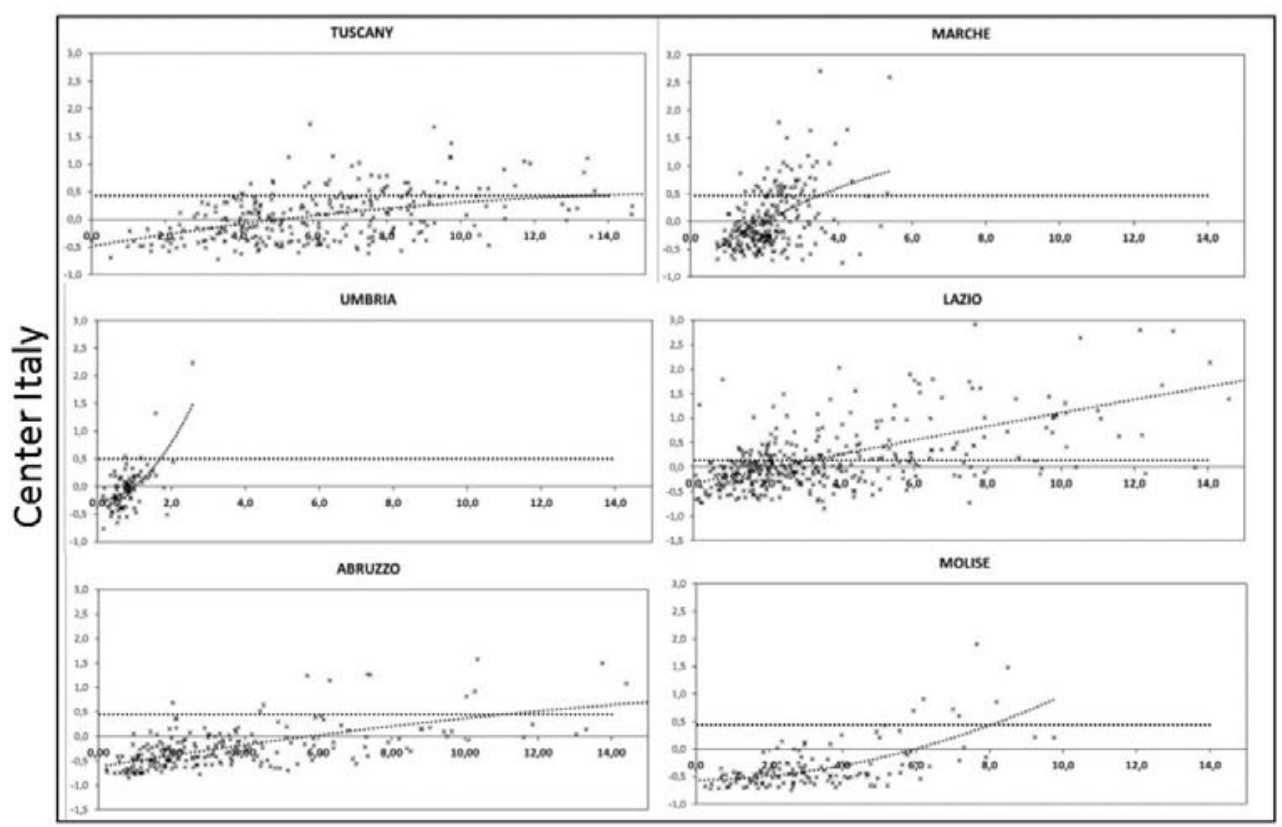

Figure 2: Relationship between urban rate increasing ( $\%-\mathrm{x}$ axis) and demographic rate increasing $(\%-y$ axis) on a municipal scale in some Italian regions.

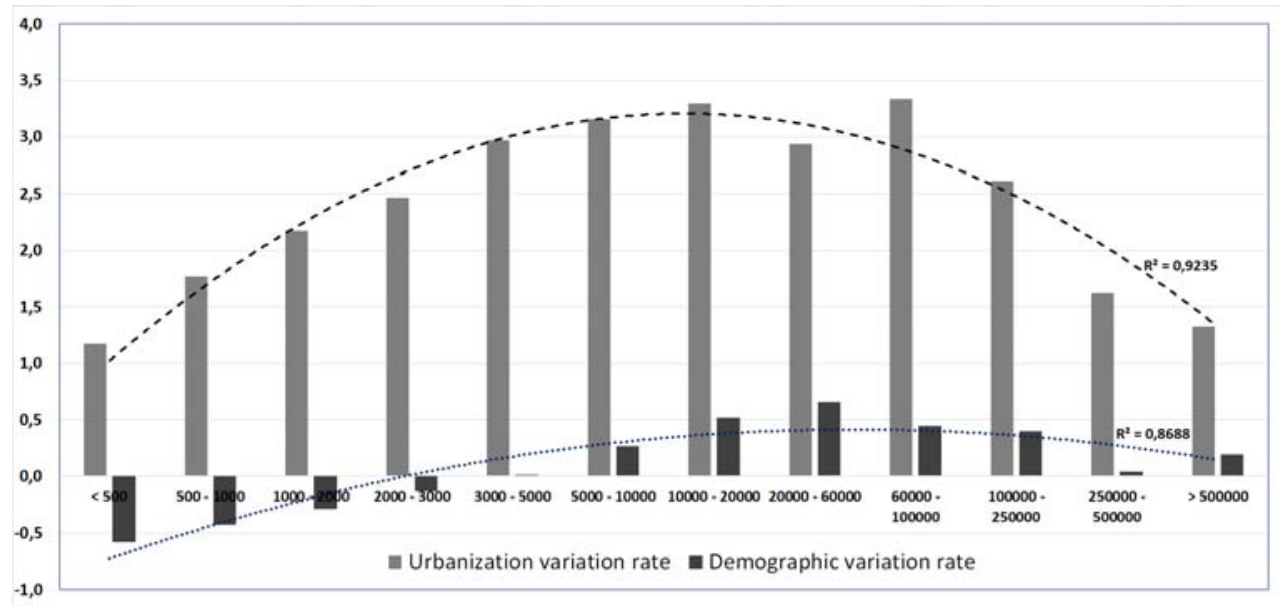

Figure 3: Population and urbanization dynamics per category of Italian municipalities.

and urban change ( $\Delta \mathrm{Urb})\left(\mathrm{R}^{2}\right.$ greater than 0.80 and up to 0.98 ). Small towns (up to 3,000 inhabitants) have lost their population, and quite significantly too, although their urbanized areas have increased and even doubled. The towns with the most significant dynamics are 
those of about 60,000 inhabitants (medium-sized towns by Italian standards), where population rise amounting to about $50 \%$ is matched by an increase in urbanized areas exceeding 300\% (6-fold higher). Almost stable population dynamics and urbanization increases by one-and-a-half fold can be found again in metropolitan areas with over 250,000 inhabitants.

The similar dynamics shared by large municipalities ( $>200,000$ inhabitants) across Italy should be considered separately: in half a century, the greatest changes are not found within these municipalities, rather in the ring of surrounding municipalities within a range of 10 $\mathrm{km}$. Indeed, while large municipalities have a $\Delta \mathrm{Urb}=136 \%$ and a $\Delta \mathrm{Dem}=14 \%$, corresponding values in their respective hinterlands are $200 \%$ and $38 \%$, thus confirming a well-known urban dispersion trend undoubtedly common to many countries, but which in Italy has far more serious problematic features, as will be discussed later.

Based on census and administrative data, the demo-urban contradiction indices (DUIDUC) highlight cases where urban and population growth match over a given period of time. The DUI helps select municipalities where the increase in urbanized areas is matched by population growth, while the DUC establishes a correlation between demographic decline and increase in urbanized areas (Fig. 4(a), (b)). These indices are expressed in per capita urbanized/built-up areas and per inhabitant acquired or lost, effectively highlighting extreme cases of actual residential/economic needs or, in the opposite case, considerable urban growth in areas marked by significant demographic decline (holiday homes and illegal buildings).

$$
\begin{aligned}
& D U I=\frac{\Delta u r b\left(a_{1}-\sigma_{11}\right)}{\Delta p o p_{\left(0_{1}-\sigma_{1}\right)}}\left(m^{2} / \text { inhab. }\right), \\
& D U C=\frac{\Delta w r b_{\left(Q_{1}-\sigma_{1}\right)}}{-\Delta p o p_{\left(0_{1}-\sigma_{1}\right)}}\left(m^{2} / \text { lost inhab. }\right),
\end{aligned}
$$

where:

$\Delta \mathrm{urb}_{(01-51)}=$ Difference between urbanized areas in municipalities between the $50 \mathrm{~s}$ and the noughties $\Delta \operatorname{pop}_{(01-51)}=$ Variation in population residing in municipalities between the $50 \mathrm{~s}$ and the noughties $-\Delta \operatorname{pop}_{(01-51)}=$ Demographic decline in municipalities between the $50 \mathrm{~s}$ and the noughties

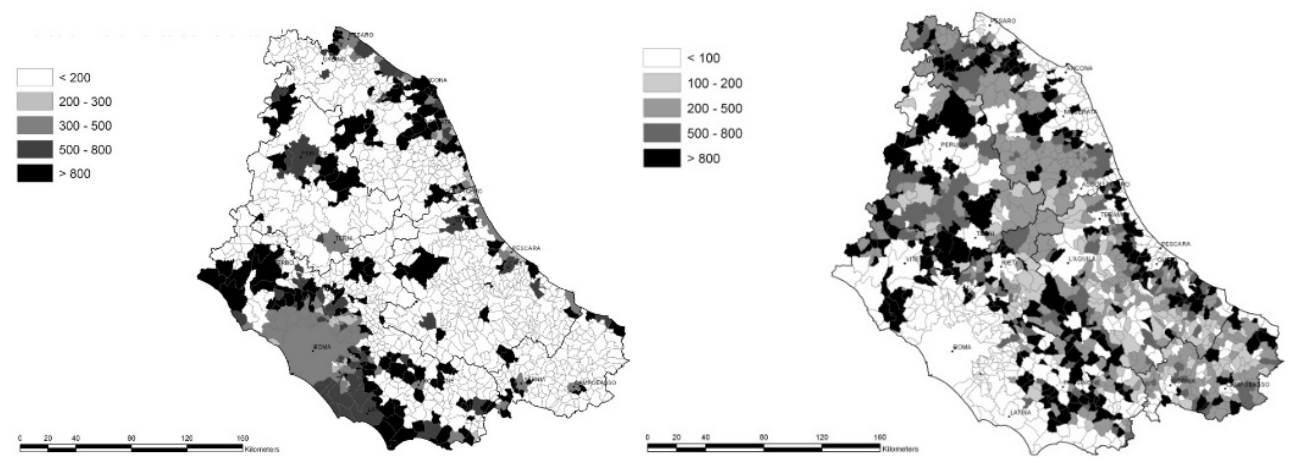

Figure 4: (a) Map to select the positive values of the demo-urban increment index (DUI); (b) Map of the demo-urban contradiction index (DUC). 


\subsection{Indicators of landscape and environmental matrix pressure}

One of the major effects of widespread urbanization is the fragmentation of habitats and biodiversity hot spot ecosystems [27], [28]. The urbanization-induced ecosystem fragmentation index (UFI) describes urbanization density weighted by means of a shape factor (Fig. 5). The first term of the expression provides the incidence of urbanized areas in the reference (administrative or grid) area, while the second term represents the ratio between the overall perimeter of urbanized areas and the perimeter that these areas would have if they were all concentrated in a single round-shaped aggregation. This index highlights the prevalence of linear urbanization along roads that causes occlusion effects for potential biotic flows of four-footed animals.

$$
U F I=\frac{\sum A u r b_{i}}{A u} * \frac{\sum p_{i}}{2 \sqrt{\pi \sum A u r b_{i}}},
$$

where:

$\mathrm{A}_{\text {urbi }}=$ urbanized areas

$\mathrm{A}_{\mathrm{u}}=$ surface of reference territorial unit

$\mathrm{p}_{\mathrm{i}}=$ perimeters of urbanized areas

A particularly adverse effect caused by urbanization on natural areas is the isolation of surrounding matrices. To this end, some parameters have been developed to measure this isolation applied to Natura 2000 habitats found within Sites of Community Interest (SCIs).

In this paper, the patches considered are SCIs that are highly dispersed throughout the country and the buffer radial step is equal to $500 \mathrm{~m}$ and therefore, the distances considered were: 500, 1000, 1500, 2000 and $2500 \mathrm{~m}$ (Fig. 6). Buffer depth, intended as the radial segment of patch edges, is always constant. Buffer generation around patches leads to reduced distances between them, until the buffers created overlap and are joined together, as a result of aggregation. This leads to a new layout where the number of patches actually drops and allows us to correlate buffer distances and number of patches, up to the extreme value of one patch, when all original patches are joined together. Hence, it is possible to plot curves correlating buffer distances and number of patches (fragmentation reduction curves), as shown in Fig. 6 for the Umbria Region.

Then, using this data, we developed fragmentation reduction curves by plotting buffer distance on the $\mathrm{x}$-axis and the Fragmentation Reduction Rate (FRR) on the y-axis.

Considering an order 1 buffer and subsequent order $1+\mathrm{i}$ buffers, the FRR value is:

$$
F R R=\frac{N p_{(1+\eta)}}{N p_{(1)}}
$$
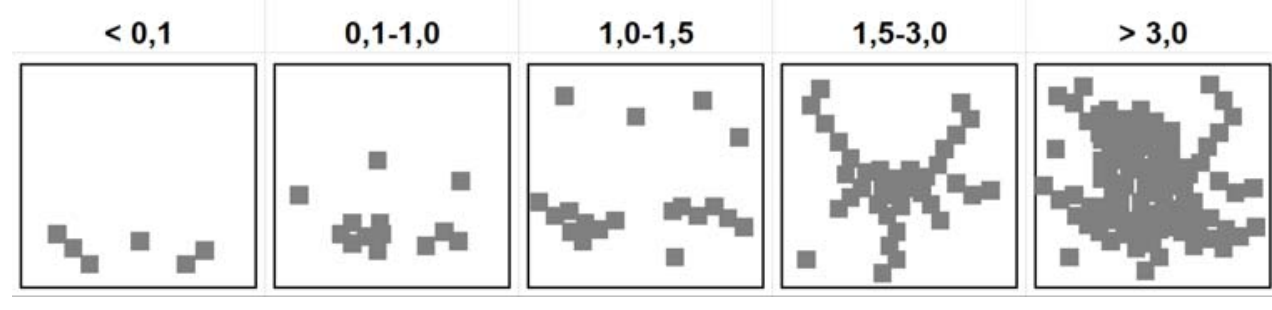

Figure 5: Sampling of the UFI index value range. 


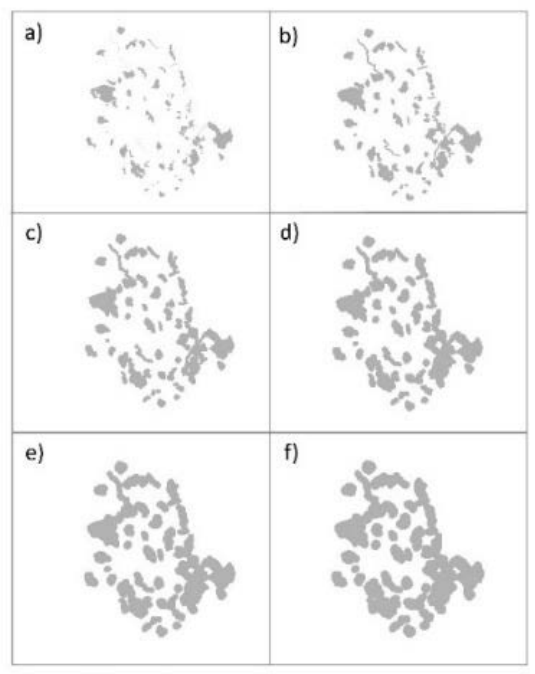

Fragmentation reduction curve

\begin{tabular}{|c|c|c|c|c|}
\hline & N. patches & Buffer distance & FRR & FRP \\
\hline a) & 97 & 0 & 1 & 0 \\
\hline b) & 56 & 500 & 0,58 & 0,42 \\
\hline c) & 48 & 1000 & 0,49 & 0,14 \\
\hline d) & 34 & 1500 & 0,35 & 0,29 \\
\hline e) & 25 & 2000 & 0,26 & 0,26 \\
\hline f) & 18 & 2500 & 0,19 & 0,28 \\
\hline
\end{tabular}

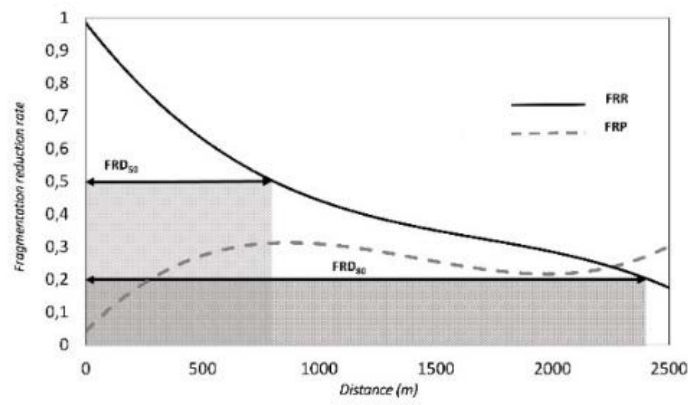

Figure 6: FRD index calculation method: buffer aggregation graph with a constant radial segment $(500 \mathrm{~m})$, using the example of the Umbria Region.

where:

$\mathrm{Np}_{(1)}=$ number of patches deriving from aggregation with an order 1 buffer

$\mathrm{Np}_{(1+\mathrm{i})}=$ number of patches deriving from aggregation with an order $1+i$ buffer

The fragmentation reduction curve shows that as buffer distance grows, patches are increasingly joined together, with an ensuing increase in environmental continuity. Using functions that express fragmentation curves (generally third grade polynomial), it is possible to calculate fragmentation reduction distances (FRDx), intended as those where the current subdivision of patches is reduced by a given rate: for example, FRD shows an aggregation distance equal to a $50-80 \%$ reduction.

In addition to FRR and FRD, another index called Fragmentation Reduction Performance (FRP) was created, which corresponds to the aggregate patch reduction ratio, while moving from one buffer to the next.

Considering an order $m$ buffer and subsequent $m+1$ buffers, the FRP value is:

$$
F R P=1-\frac{N p_{(m+1)}}{N p_{(m)}}
$$

where:

$\mathrm{Np}_{(\mathrm{m})}=$ number of patches deriving from aggregation with an order $\mathrm{m}$ buffer $\mathrm{Np}_{(\mathrm{m}+1)}=$ number of patches deriving from aggregation with an order $\mathrm{m}+i$ buffer

This index shows the buffer joining distance with the highest level of aggregation, where it seems to the more convenient to invest plan and project resources, in order to achieve continuity among Nature 2000 sites [29]. Fig. 7 shows the fragmentation reduction curves of SICs/SACs in some Italian regions, highlighting the three, previously defined parameters. 

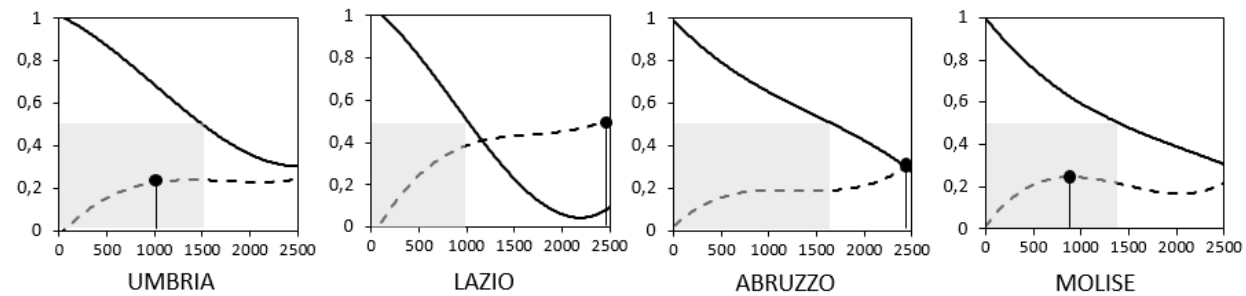

Figure 7: Fragmentation reduction curves of SCIs/SACs in some Italian regions. On the $y$ axis the FRR values and on the $x$ axis buffer distances. In grey the $\mathrm{FRD}_{50}$ values, while the dotted curve is the $\mathrm{FRP}_{\max }$ (Fragmentation Reduction Performance) index.

\section{CONCLUSION}

The examples of indicators discussed in this paper are part of a broader panel developed to respond to the requirements of public agencies to monitor the conditions of their respective territories, in order to support current and strategic management decisions (Decision Support System - SSD). This approach is followed more and more and taps present-day technology to produce and process data.

Hence, the significant importance of "indicator engineering" that has to be able to design sets of indicators capable of capturing any changes in land use, using a multi-criteria approach, in accordance with the governance and control powers of the various administrative bodies (municipalities, regions, reclamation agencies, civil protection, parks and reserves), thus assuring the utmost interoperability and transparency of information. The correct and widespread use of official indicator panels helps set up correlation platforms that provide warnings when certain thresholds are reached, thus making it possible to implement adaptive control actions, with a view to achieving the desired results of plans and programmes. The careful design and optimisation of panels could help boost the quantity and quality of acquired information (fast monitoring) and significantly reduce the cost of collecting and processing primary data, following the gradual and widespread use of open source GIS systems.

Unfortunately there is still some reluctance towards innovative techniques and procedures, especially among public authorities: it is sufficient to consider that many Italian municipalities do not have their own SITs (Territorial Information Systems), nor a digital PRG (Land Planning Tool). Yet, today speed has become an essential aspect in planning. "Slow" planning is of no use and is already dated when ready to be implemented. Fast Planning can help overcome pressing issues in an adequate amount of time, assuring consistency with the strategic level of governance. In Fast Planning GIS, UAVs (Unmanned Aerial Vehicle) and RS (Remote Sensing) play a key role, by establishing the previously described multi-indicator and multi-criteria procedures at a multi-scale level. The key to this process is the full use of available technology, by resorting to scenario simulation analyses and introducing control techniques to modulate outcomes according to the expectations of stakeholders and public authorities, also in view of the goals established at European level to reduce land take by 2050 [30].

\section{REFERENCES}

[1] European Commission, Urban Sprawl in Europe: The ignored challenge, EEA Report N. 10, 2006. 
[2] Ellis, C.E. \& Ramankutty, N., Putting people in the map: Anthropogenic biomes of the world. Frontier in Ecology and the Environment, 6(8), pp. 439-447, 2008.

[3] Safirova, E., Houde, S. \& Harrington, W., Spatial Development and Energy Consumption, RFF DP 07-51, Washington, 2007.

[4] Carruthers, J.I. \& Ulfarsson G.F., Urban sprawl and the cost of public services. Environment and Planning B, 30(4), pp. 503-522, 2003. DOI: 10.1068/b12847.

[5] Travisi, C.M., Camagni, R. \& Nijkamp, P., Impacts of urban sprawl and commuting: A modelling study for Italy. Journal of Transport Geography, 18(3), pp. 382-392, 2010. DOI: $10.1016 /$ j.jtrangeo.2009.08.008.

[6] Collinge, S.K., Ecological consequences of habitat fragmentation: Implications for landscape architecture and planning. Landscape and Urban Planning, 36(1), pp. 5977, 1996. DOI: 10.1016/s0169-2046(96)00341-6.

[7] Fahrig, L., Effects of habitat fragmentation on biodiversity. Annual Review of Ecology, Evolution, and Systematics, 34, pp. 487-515, 2003.

[8] Battisti, C., Habitat fragmentation, fauna and ecological network planning: Toward a theoretical conceptual framework. Italian Journal of Zoology, 70, pp. 241-247, 2003. DOI: 10.1080/11250000309356524.

[9] Bennett, A.F. \& Saunders, D.A., Habitat fragmentation and landscape change. Conservation Biology for All, Oxford University Press, pp. 88-106, 2010.

[10] Dupras, J. \& Alam, M., Urban Sprawl and ecosystem services: A half century perspective in the Montreal Area (Quebec, Canada). Journal of Environmental Policy \& Planning, 17(2), pp. 180-200, 2015. DOI: 10.1080/1523908x.2014.927755.

[11] Frumkin, H., Urban sprawl and public health. Public Health Reports, 117(3), pp. 201-217, 2002. DOI: 10.1093/phr/117.3.201.

[12] Salvati, L., Munafò, M., Morelli, G.V. \& Sabbi, A., Low-density settlements and land use changes in a Mediterranean urban region. Landscape and Urban Planning 105(1-2), pp. 43-52, 2012.

[13] Squires, G.D., (ed), Urban Sprawl: Causes, Consequences, \& Policy Responses, The Urban Institute Press: Washington D.C., p. 368, 2002.

[14] The Worldwatch Institute, State of the World, Our Urban Future, Norton: New York, p. 250, 2007.

[15] Ewing, R.H., Characteristics, causes, and effects of Sprawl: A literature review. Urban Ecology, eds. J.M. Marzluff et al., pp. 519-535, 2008.

[16] Angel, S., Parent, J. \& Civco, D., The fragmentation of urban landscapes: Global evidence of a key attribute of the spatial structure of cities, 1990-2000. Environment and Urbanization, 24, pp. 249-283, 2012. DOI: 10.1177/0956247811433536.

[17] Batty, M., The theory of city size. Science 340(6139), pp. 1418-1419, 2013.

[18] Barrington-Leigh, C. \& Millard-Ballb, A., A century of sprawl in the United States. Proceedings of the National Academy of Sciences, 112(27), pp. 8244-8249, 2015.

[19] Paleari, S., Is the European Union protecting soil? A critical analysis of community environmental policy and law. Land Use Policy 64, pp. 163-173, 2017.

[20] Romano, B., Zullo, F., Fiorini, L., Ciabò, S. \& Marucci, A., Sprinkling: An approach to describe urbanization dynamics in Italy. Sustainability, 9(1), p. 97, 2017. DOI: 10.3390/su9010097.

[21] Romano, B. \& Zullo, F., Land urbanization in central Italy: 50 years of evolution. Journal of Land Use Science, 9(2), pp. 143-164, 2012. DOI: 10.1080/1747423x.2012.754963. 
[22] Romano, B. \& Zullo, F., Models of urban land use in Europe: Assessment tools and criticalities. International Journal of Agricultural and Environmental Information Systems, 4(3), pp. 80-97, 2013.

[23] Romano, B. \& Zullo, F., The urban transformation of Italy's Adriatic coast strip: Fifty years of unsustainability. Land Use Policy, 38, pp. 26-36, 2014. DOI: 10.1016/j.landusepol.2013.10.001.

[24] Güneralp, B. \& Seto, K.C., Futures of global urban expansion: Uncertainties and implications for biodiversity conservation. Environmental Research Letters B, 8(1), p. 014025,2013 . DOI: 10.1088/1748-9326/8/1/014025.

[25] Güneralp, B. et al., Global scenarios of urban density and its impacts on building energy use through 2050. Proceedings of the National Academy of Sciences, 114(34), pp. 8945-8950, 2017.

[26] Romano, B., Zullo, F., Fiorini, L., Marucci, A. \& Ciabo, S., Land transformation of Italy due to half a century of urbanisation. Land Use Policy, 67, pp. 387-400, 2017. DOI: 10.1016/j.landusepol.2017.06.006.

[27] Irwin, E.G. \& Bockstael, N.E., The evolution of urban sprawl: Evidence of spatial heterogeneity and increasing land fragmentation. Proceedings of the National Academy of Sciences, 104(52), pp. 20672-20677, 2007.

[28] Romano, B. \& Zullo, F., Landscape fragmentation in Italy. Indices implementation to support territorial policies. Planning Support Tools: Policy Analysis, Implementation and Evaluation, eds. M. Campagna, A. De Montis, F. Isola, S. Lai, C. Pira \& C. Zoppi, Franco Angeli, pp. 399-414, 2012.

[29] Marucci, A. et al., Spatial Methods to Measure Natura 2000 Sites Insularization in Italy. Computational Science and Its Applications-ICCSA 2017. Lecture Notes in Computer Science, eds O. Gervasi et al., vol. 10407. Springer: Cham, ICCSA, 2017.

[30] European Commission, Future brief: No net land take by 2050? CE, 14, 2016. 